\title{
Asia como destino de la Inversión Extrajera Directa
}

\author{
Asia as a destination for Direct Foreign Investment
}

\author{
Ruth Ortiz-Zarco ${ }^{a}$
}

\begin{abstract}
:
The purpose of this document is to provide a recent overview of the behavior of foreign direct investment (IED) in Asia, including a brief analysis of its determinants, the study period 2005-2016, is selected with the intention of collecting the effects emanating from the subprime financial crisis.
\end{abstract}

Keywords:

Foreign Direct Investment, Asia, Subprime Financial Crisis.

\section{Resumen:}

El objetivo de este documento es brindar un panorama reciente del comportamiento de la inversión extranjera directa (IED) en Asia, incluyendo un breve análisis de sus determinantes, el periodo de estudio 2005-2016, se selecciona con miras a recoger los efectos emanados de la crisis financiera subprime.

Palabras Clave:

Inversión Extranjera Directa, Asia, Crisis Financiera Subprime.

\section{Introducción}

El desarrollo económico de las décadas recientes está marcado por el creciente posicionamiento de las economías asiáticas en el mundo, cuya capacidad de adaptación al nuevo régimen de globalización, mediante su apertura al mercado mundial, les ha permitido incrementar su comercio exterior, sus intercambios financieros y la movilidad de IED. La integración económica mundial, involucra el análisis de diversas variables económicas, en este documento, debido a su relevancia se analiza el comportamiento de la IED en las principales economías Asiáticas, pues las características de su estructura productiva (salarios, productividad, procesos productivos, recursos naturales, etc.), la convierten en una importante región receptora de IED, pese a las divergencias de la regulación entre países.

La UNCTAD (2017) considera que la IED es la fuente de financiación externa más importante y constante para las economías en desarrollo, para el caso específico de Asia (a excepción de Asia Meridional), el 2016 fue un año de contracción del $15 \%$ en los flujos de IED, fue la primera disminución en cinco años, la caída se debe principalmente a una baja en las inversiones de las empresas multinacionales europeas, mientras que China pasó a convertirse en el segundo país inversionista más importante del mundo, registrando un importante incremento en sus inversiones, lo que corresponde con su disminución de tenencias de bonos estadounidenses, en su deseo por fortalecer el yuan frente al dólar y posicionarlo como moneda mundial. ${ }^{1}$

Las agentes económicos promotores de la IED son las empresas multinacionales, que básicamente por medio de fusiones y adquisiciones, han expandido el capital a lo largo del mundo, al tiempo que lo concentran en pocos propietarios. De acuerdo con la UNCTAD (2017), la nueva base de datos de empresas multinacionales revela una importancia creciente de la propiedad estatal, $1.5 \%$ del total de empresa multinacionales se encuentran ahora en manos del estado, y sus empresas matrices están bastante dispersas, poco más de la mita se localizan en economías en desarrollo, y nuevamente China aparece como principal lugar de procedencia con el $18 \%$, seguida de Malasia, que posee el $5 \%$ y la India con un $4 \%$; si bien las empresas multinacionales de propiedad estatal son pocas, 15 de las 100 principales multinacionales no 
financieras a nivel mundial y 41 de las 100 principales multinacionales de las economías en desarrollo y en transición son de propiedad estatal. ${ }^{1}$

Un elemento adicional, consiste en la relevancia económica de las empresas multinacionales digitales, las cuales se están posicionando fuertemente, según la UNCTAD (2017) cerca del $70 \%$ de sus ventas las realizan en el extranjero, mientras que el $40 \%$ de sus activos están fuera de su país de origen; el auge de las multinacionales digitales, es gracias a que enlazan la producción internacional y el comercio de bienes, al tiempo que reducen los costos y facilitan la administración de las filiales a la distancia; la limitante de estas empresas es su difícil inserción en mercados emergentes que no cuentan con la infraestructura requerida en tecnologías de información y comunicación, por lo que aquellos países que quieran participar de los beneficios de esta nueva era, requieren inversión en infraestructura adecuada.

La crisis subprime tuvo efectos generalizados, cuyas secuelas no han terminado, pero la IED continuó con un flujo estable como medio de financiamiento internacional; desde luego la incertidumbre no se elimina y por ello las empresas transnacionales al buscar estrategias que incluyan nuevos mercados emergentes, se enfocan en regiones y mercados que brindan mayor seguridad, tal es el caso de Asia; por ello aquí se realiza un esbozo de los movimientos de la IED en Asia, para lo cual, a esta introducción le siguen un análisis estadístico y un bosquejo de los determinantes de la misma.

\section{Determinantes de la IED}

La literatura que indaga los determinantes de la IED es extensa y data de años atrás, sin embargo, pese al paso del tiempo los planteamientos teóricos siguen vigentes y son la base de nuevos esbozos. Hymer (1958) consideraba que la IED por parte de las empresas multinacionales, es consumada por el anhelo de aprovechar el mercado externo, y la empresa la justifica por su posesión de activos intangibles (marcas, procesos de gestión empresarial, desarrollo de su tecnología). ${ }^{2}$ Poco después Vernon (1966), plantea la teoría de las tres etapas del ciclo de vida del producto (gestación, estandarización y maduración), como una explicación del desfase en la internacionalización de las empresas ${ }^{3}$; afirmando que el objetivo que persigue la IED es mantener una determinada cuota de mercado adquirida a través de la exportación, relegando a un segundo plano los costos relativos; contrariamente Helpman y Krugman (1985) afirman que los flujos de IED, se explican esencialmente por el deseo de minimizar los costos de los factores de producción y dado que las dotaciones de factores productivos se distribuyen en diversos países, las empresas segmentan su cadena productiva, ubicando cada etapa en el país que minimice los costos. ${ }^{4}$

La visualización de la IED como flujos de capital financiero, fue planteada por Kojima (1976), que afirma que básicamente, la IED está determinada por la existencia de factores productivos y menores costos de producción; bajo este planteamiento, la IED es perpetrada por empresas productoras de bienes intermedios para cuya fabricación se necesitan recursos provenientes del país inversor, que genera actividades productivas que demandan recursos escaseados en el país receptor. ${ }^{5}$

Uno de los autores con mayor peso en el estudio de los determinantes de la IED ha sido Dunning, quien detalla los requerimientos de una empresa multinacional para adentrarse a una economía, se engloban en tres: ventajas específicas de propiedad por parte de la empresa, ventajas de localización de los países destino de la IED y ventajas de la internalización del proceso productivo; a los elementos anteriores se suma la importancia de: el tamaño del mercado, la infraestructura, las características institucionales, la estabilidad macroeconómica y la dotación de factores de producción, Dunning (1977) ${ }^{6}$. Posteriormente, discurre que el destino de la IED obedece a 4 factores: existencia de recursos naturales, el desarrollo de mercados, la eficiencia productiva y la presencia de activos estratégicos, Dunning (1994). ${ }^{7}$

Para Ozawa (1992), la ubicación de los flujos de IED, se determina por los rasgos propios de las economías menos desarrolladas; los bajos salarios y la abundancia de recursos naturales sin explotar, son elementos que atraen la IED, incitando cambios estructurales en la economía receptora, entre ellos, el aumento del nivel de ingresos y en consecuencia una modificación de la demanda interna; si los cambios perduran, esa economía puede convertirse en sede de matrices de empresas multinacionales, que posteriormente generaran flujos de IED dirigidos a países con menor nivel de ingresos. ${ }^{8}$

Respecto a la literatura que indaga los terminantes de la IED en Asia, es amplia y reciente, tal como lo es el surgimiento de Asia como destino predilecto de IED; Sjöholm (2013) atraído por los crecientes flujos de IED en el Sudeste Asiático, analiza su conducta y determinantes; ultimando, que son dos los elementos decisivos de las EIED, el primero es el cambio tecnológico que permite una integración más estrecha entre países y el segundo es una transformación en la ideología de los gobiernos y los responsables de la formulación de la políticas económicas, orientada a la aceptación de la globalización, liberalización de mercados y empresas multinacionales; a estas dos mejoras se suman: el cambio institucional, la localización geográfica, la estabilidad política y macroeconómica. ${ }^{9}$

La fundación BBVA (2010), considera que los elementos que coadyuvaron a la EIED en el continente asiático son: 
una elevada dotación inicial de mano de obra, el fomento de exportaciones manufacturadas intensivas en mano de obra, la metamorfosis demográfica de la segunda posguerra (mayor cantidad de población en edad de trabajar, generando incrementos de ahorro e inversión), y las características geográficas favorables, principalmente el acceso al mar; la SIED se justifica por la obtención de recursos naturales, mano de obra de bajo coste y el acceso a mercados mayores o en crecimiento. ${ }^{10}$

Una vez realizada una breve revisión de los elementos que inciden en las EIED y SIED, es pertinente analizar los datos disponibles.

\section{Flujos de IED en las principales economías asiáticas}

Para conocer el comportamiento de la IED en las principales economías asiáticas, se presentan 14 gráficas, cada una corresponde a las EIED (entradas de inversión extranjera directa) y SIED (salidas de inversión extranjera directa) en dólares, de los siguientes países: Brunei, Camboya, India, Indonesia, China, Corea del Sur, Filipinas, Bangladesh, Japón, Malasia, Tailandia, Singapur y Vietnam. El análisis gráfico muestra serias variaciones, tanto a lo largo del tiempo como entre países; los países con mayor producción y crecimiento (China, Japón y Corea del Sur), se caracterizan por una SIED superior a la EIED; dos países son la excepción durante el periodo de estudio, India e Indonesia presentan elevada producción y crecimiento, pero aún no poseen una elevada capacidad para exportar capitales, el desarrollo de su capitalismo, se encuentra en una fase intensiva a diferencia de las economías más desarrolladas de Asia que viven una fase extensiva del capitalismo.

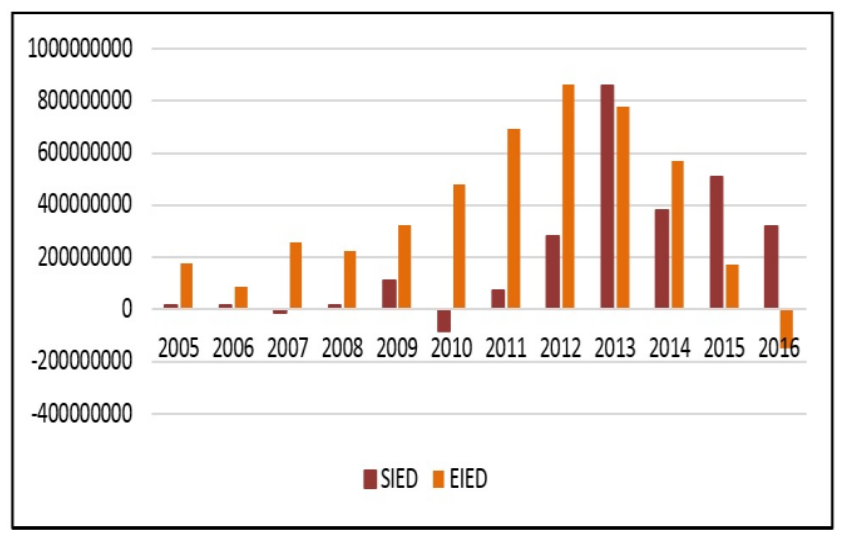

Gráfica 1. Salidas (SIED) y Entradas (EIED) en Brunei Darussalam

Fuente: Elaboración propia con datos del BM (2018)

Brunei es un pequeño país poseedor de un enorme potencial económico, sustentado por sus reservas de petróleo y gas natural, a lo cual se suma la estabilidad política de su sistema político; en el periodo posterior a la crisis financiera subprime las EIED crecieron continuamente hasta 2013 (ver gráfica 1), periodo en que comienza su caída acompañada de una tasa de crecimiento baja; la economía enfrenta un momento difícil, pero no deja de ser un destino atractivo para la IED.

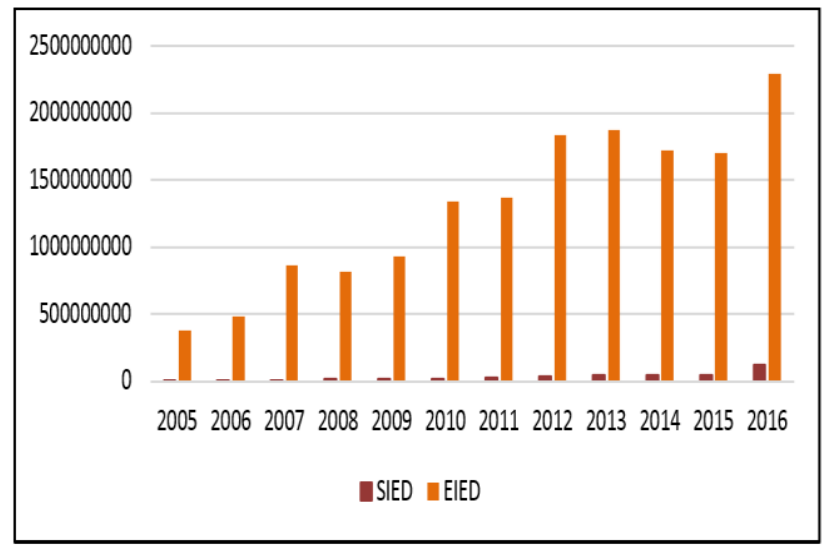

Gráfica 2. Salidas (SIED) y Entradas (EIED) en Camboya

Fuente: Elaboración propia con datos del BM (2018)

Camboya es actualmente el país menos desarrollado de Asia Oriental y uno de los más pobres del mundo; de acuerdo a Cortiñas (2015) a fines de los años 80's paso de ser una economía de planificación central a una de mercado y en el 2003 ingresó a la OMC ${ }^{11}$; liberalizando el comercio y las finanzas, convirtiéndose en un importante receptor de IED (ver gráfica 2), la crisis financiera subprime, no mermó lo flujos de inversión; cuyos orígenes esenciales son: Malasia, Taiwán, Estados Unidos, China y Vietnam; las EIED han sido decisivas en el desarrollo y crecimiento económico del país.

La India, se ha convertido en uno de los principales destinos de IED desde 2005, las EIED superan por mucho a las SIED (ver gráfica 3), lo cual es resultado de la liberalización de la política de IED por parte del gobierno, que además ha asociado algunos sectores a un proceso de aprobación automática; como ventajas, India es uno de los mercados mundiales más poblados, con mayor crecimiento, poseedor de una favorable demografía, un sistema de gobierno democrático y estable, un marco regulatorio competitivo y un sector privado emprendedor; desafortunadamente carece de infraestructura física y social, las leyes laborales son rígidas y tiene una oferta limitada en los sectores energético, metalúrgico y alimentario, Deorukhkar y García (2015). ${ }^{12}$ 


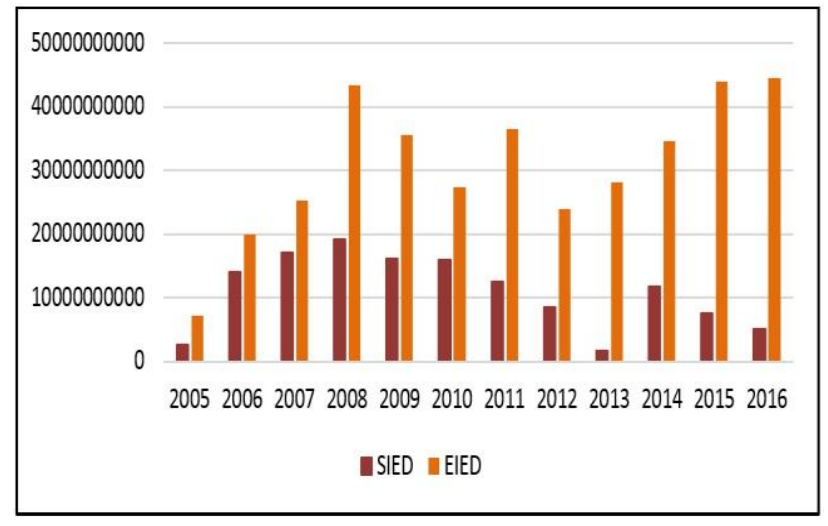

Gráfica 3. Salidas (SIED) y Entradas (EIED) en India

Fuente: Elaboración propia con datos del BM (2018)

En el periodo de estudio, Indonesia presenta una tendencia creciente de las EIED, que se ve interrumpida en el 2015, y peor aún muestra una importante caída en el 2016 (ver tabla 4), el clima de incertidumbre por conflictos religiosos es un factor que perjudica los flujos habituales de inversión, la agricultura es la actividad económica principal, y los ingresos externos provienen de la venta de petróleo y gas natural; su relación con China y sus recursos naturales son factores determinantes de la llegada de IED.

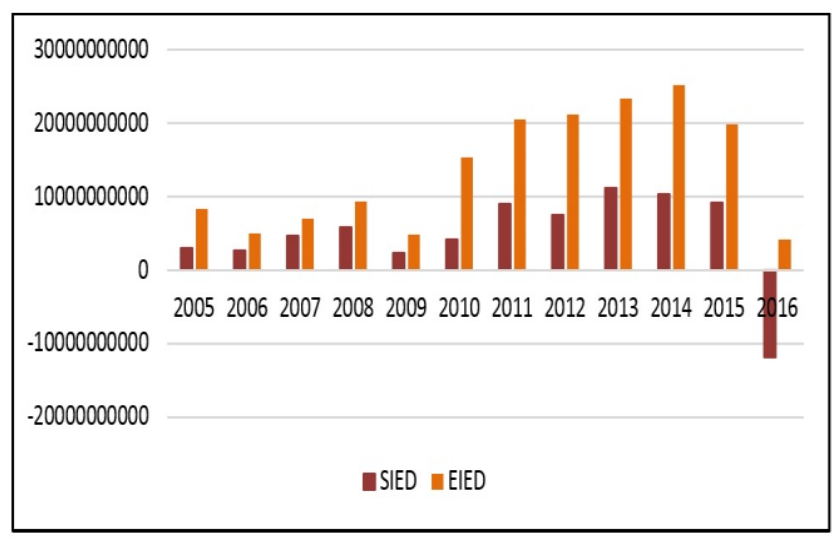

Gráfica 4. Salidas (SIED) y Entradas (EIED) en Indonesia

Fuente: Elaboración propia con datos del BM (2018)

En el caso particular de China, desde su ingreso en la Organización Mundial del Comercio (OMC) en 2001, se consolidó como el principal receptor de IED del mundo en desarrollo: en la última década recibió un promedio de 50.000 millones de dólares al año, Correo y González (2006), alentando principalmente inversiones de alta tecnología y energías no contaminantes; sin embargo a partir de 2016, es mayor la SIED que la EIED (ver gráfica 5), debido a que el capitalismo de China se encuentra en fase extensiva, ahora China gracias al crecimiento de su mercado, a los incentivos gubernamentales y demás acciones por parte del gobierno, no solo es atractivo para la EIED, también la SIED de este país juega un papel determinante en desarrollo de Asia y de todo el mundo. ${ }^{13}$

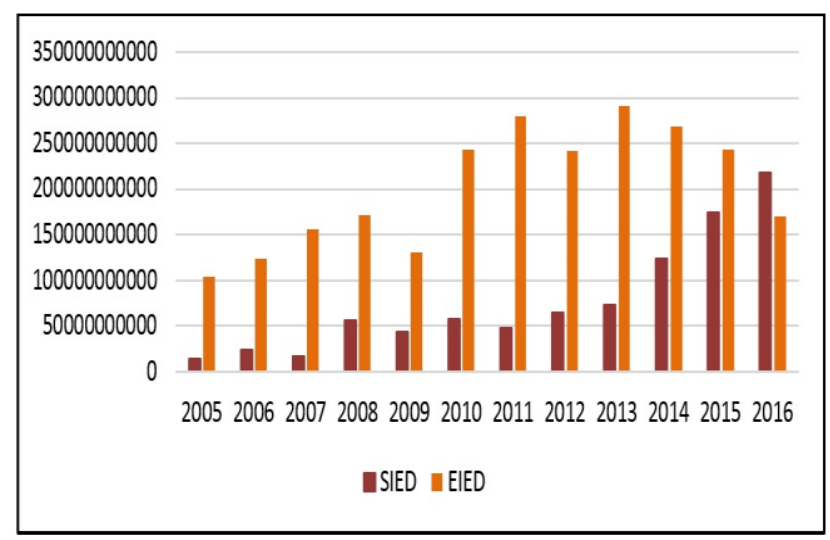

Gráfica 5. Salidas (SIED) y Entradas (EIED) en China

Fuente: Elaboración propia con datos del BM (2018)

Durante el periodo de estudio, tanto las SIED como las EIED en Corea del Sur muestran un comportamiento estable (Gráfica 6), siento mayores las salidas; la EIED se justifica por el desarrollo y especialización del sector de información y telecomunicaciones, la existencia de mano de obra calificada, la infraestructura existente; y se limita por la escasa transparencia en materia regulatoria, fuertes restricciones normativas y una mano de obra relativamente cara.

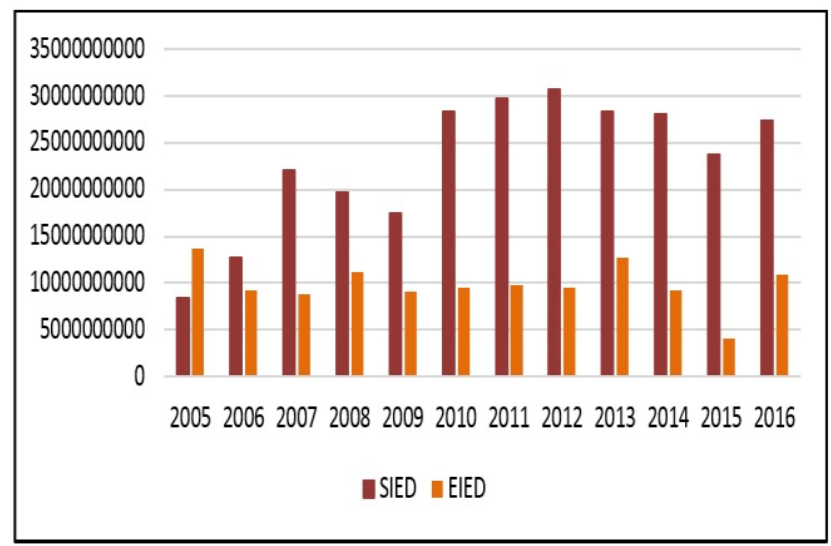

Gráfica 6. Salidas (SIED) y Entradas (EIED) en Corea del Sur

Fuente: Elaboración propia con datos del BM (2018)

El comportamiento de las EIED y SEID en Filipinas, muestran inestabilidad a lo largo del tiempo (ver gráfica 7); el 2016 significó un salto entre la inversión entrante y saliente, la EIED toca un punto histórico, su carencia de infraestructura brinda una oportunidad de inversión que se 
agudiza por su relevancia estratégica, una aceptable tasa de crecimiento económico y el bajo precio del petróleo.

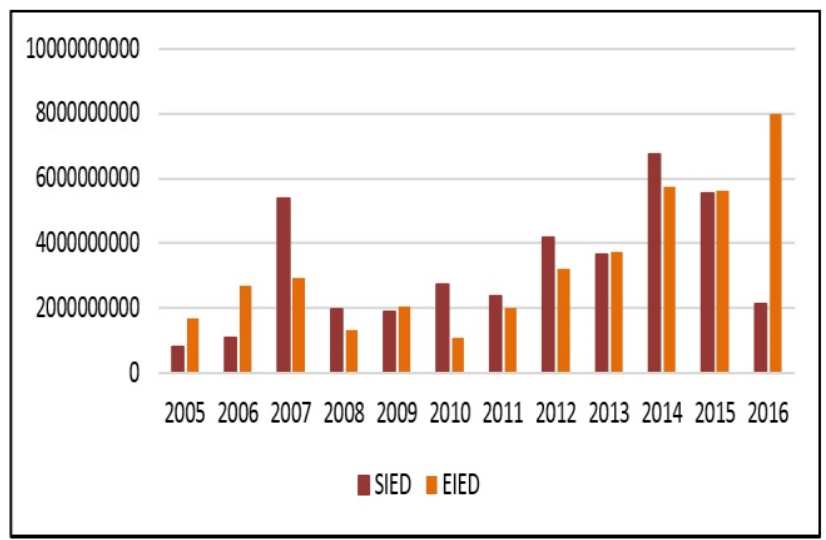

Gráfica 7. Salidas (SIED) y Entradas (EIED) en Filipinas

Fuente: Elaboración propia con datos del BM (2018)

Bangladesh es un caso muy particular, la SIED es prácticamente en inexistente, mientras los flujos de EIED son elevados y crecientes (ver gráfica 8), el motivo es el contexto tan liberal y favorable a la inversión, además de su privilegiada ubicación geográfica; gran parte de la producción de Bangladesh tiene acceso libre de cuotas a países desarrollados como Estados Unidos, Japón y la Unión Europea.

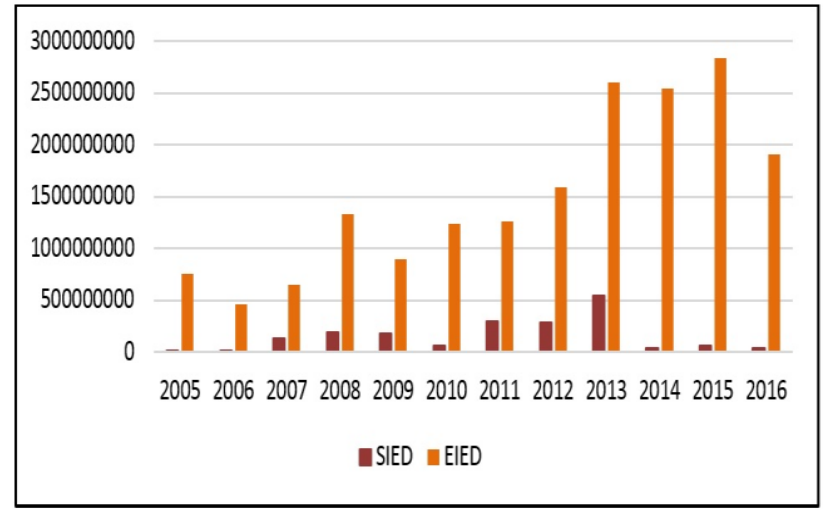

Gráfica 8. Salidas (SIED) y Entradas (EIED) en Bangladesh

Fuente: Elaboración propia con datos del BM (2018)

Japón es un caso interesante, sus condiciones económicas, tecnológicas, de infraestructura y legales son atractivas a la IED, es mucho más atrayente que un gran número de países, pero los resultados denotan que la EIED ha sido débil en todo el periodo de estudio (ver gráfica 9), siendo el idioma y la cultura de negocios dos aspectos que limitan la llegada de IED; la crisis subprime sí afectó (aunque solo en el corto plazo) los flujos de inversión, en el 2011 y 2012 las EIED fueron mínimas. La fuerza de este país, radica en su liderazgo tecnológico y en investigación y desarrollo, y eso lo mantiene posicionado como uno de los países que más invierten en el mundo.

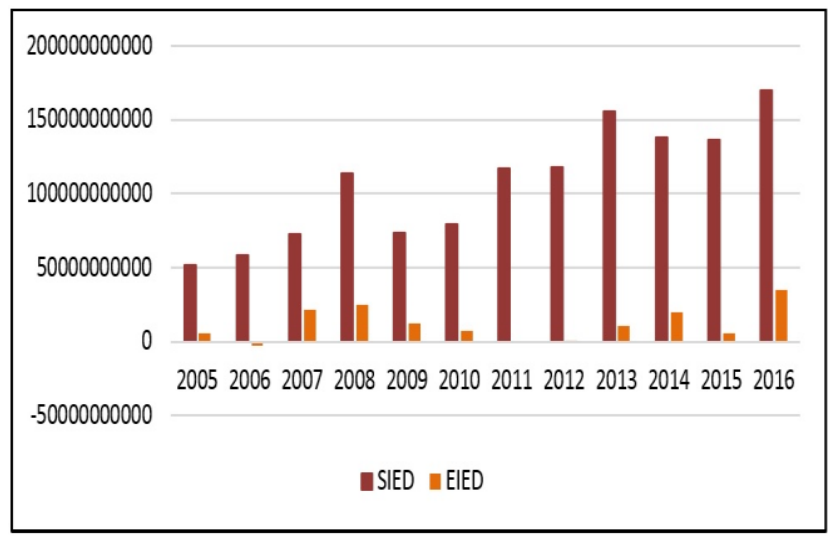

Gráfica 9. Salidas (SIED) y Entradas (EIED) en Japón

Fuente: Elaboración propia con datos del BM (2018)

Malasia es una economía recién industrializada, desde 2005 hasta 2015 la SIED superó a la EIED (ver gráfica 10), la brecha entre ambas no es tan marcada, pero el 2016 representó un año de cambio, la EIED superó a las salidas, los motivos: mejoras en materia de corrupción (descenso de los gastos públicos), libertad de empresa, estabilidad jurídica e incremento del comercio. La electrónica, la investigación científica y tecnológica en el campo de la medicina y farmacéutica, y la refinación de petróleo son las principales actividades económicas, sus principales productos de exportación son el aceite de palma y el caucho.

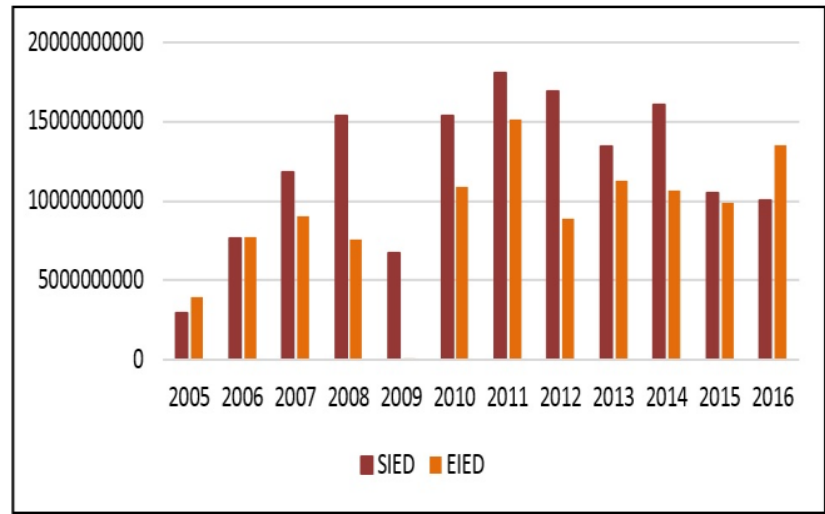

Gráfica 10. Salidas (SIED) y Entradas (EIED) en Malasia

Fuente: Elaboración propia con datos del BM (2018)

Actualmente Tailandia es una de las economías asiáticas con mayor desarrollo y crecimiento económicos, en gran medida ello se debe al crecimiento de sus exportaciones 
y su capacidad para captar IED, de 2005 a 2016, únicamente en dos periodos (2011 y 2016), la SIED ha superado a la EIED (ver gráfica 11); la crisis financiera subprime afectó tanto la entrada como la salida de IED en el 2009, posteriormente los niveles se recuperan pero recaen en el 2014 y 2015; bajo un contexto de inestabilidad global, los flujos de IED en Tailandia se afectan entre otros aspectos por sus elevados salarios, la escasa tecnología de su sistema productivo y la reciente inestabilidad política.

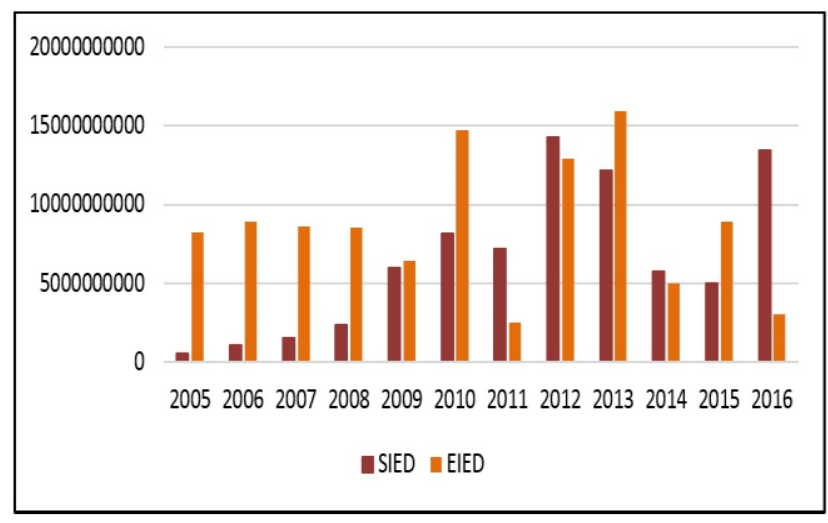

Gráfica 11. Salidas (SIED) y Entradas (EIED) en Tailandia

Fuente: Elaboración propia con datos del BM (2018)

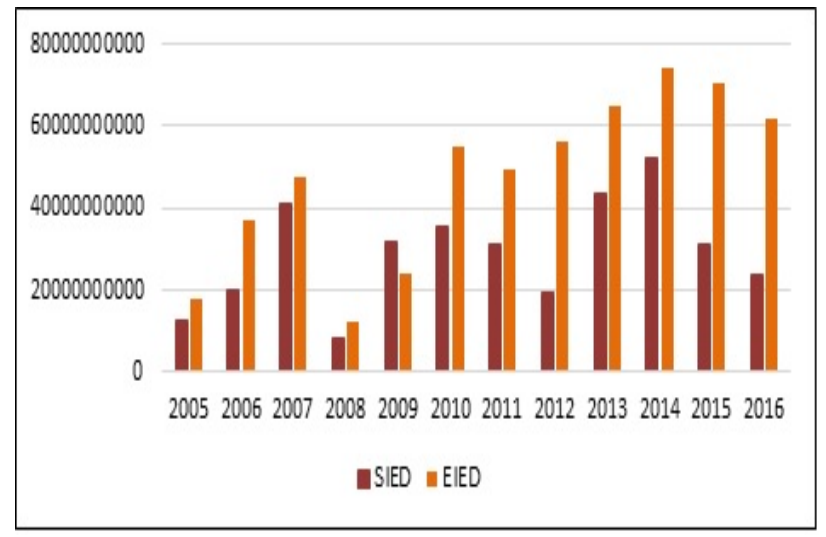

Gráfica 12. Salidas (SIED) y Entradas (EIED) en Singapur

Fuente: Elaboración propia con datos del BM (2018)

Como estrategia de crecimiento y desarrollo económicos, Singapur ha enfocado sus esfuerzos en atraer IED, durante todo el periodo de estudio la EIED ha superado a la SIED, la crisis financiera subprime si afectó los flujos de inversión, que cayeron drásticamente en 2008, retomando su nivel de crecimiento en el 2013 (ver grafica 12); algunas estrategias para fomentar la IED son: apertura comercial, ubicación geográfica, excelente infraestructura, estabilidad política, lucha contra la corrupción, sencillo sistema regulador, financiamiento a inversionistas e incentivos fiscales.

En Vietnam, las SIED con prácticamente nulas respecto de las EIED (ver gráfica 13), si se observa una ligera caída en la inversión a causa de la crisis financiera subprime, sin embargo las EIED han retomado su nivel y su tendencia; el gobierno ha corregido procesos administrativos, a fin de minimizar el tiempo y los costos a favor del ambiente empresarial, sumado a la negociación de acuerdos bilaterales y tratados comerciales; su integración al mercado mundial es reciente y su economía se sustenta en las materias primas y los procesos de producción tradicionales; sin embargo gracias a los flujos de IED el valor agregado de la producción va en aumento.

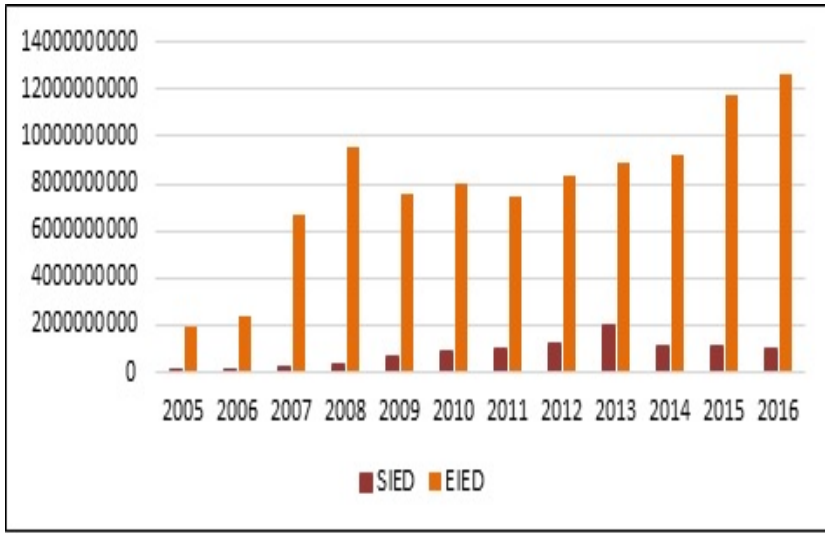

Gráfica 13. Salidas (SIED) y Entradas (EIED) en Vietnam

Fuente: Elaboración propia con datos del BM (2018)

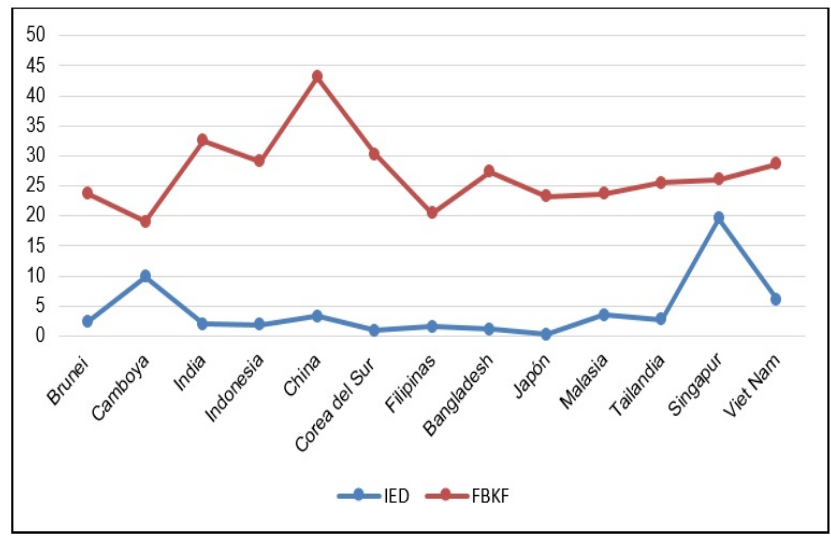

Gráfica 14. Promedio de IED y FBKF como porcentajes del $P I B$

Fuente: Elaboración propia con datos del BM (2018)

Los efectos de la crisis financiera subprime de 2008, no perjudicaron seriamente los flujos de IED en la región asiática, siento los principales receptores: Singapur, 
Tailandia, Vietnam y Malasia, seguidos de Camboya, Filipinas y Bangladesh; si se considera la IED promedio correspondiente al periodo de estudio, se observa que Singapur recibió una IED equivalente al $19.58 \%$ de su PIB, seguida de Camboya con un 9.87\%; sin embargo al contrastar estos valores con la formación Bruta de Capital Fijo (FBKF) promedio del periodo, son China $(43.03 \%$ PIB), India (32.55\% PIB), Corea (30.21\% PIB) e Indonesia $(29.03 \%)$ las naciones que lograron un mayor porcentaje respecto de su producto; Camboya fue el país con menor FBKF, equivalente al $18.97 \%$ de su PIB; la lectura es que las principales economías asiáticas no dependen de inversionistas externos para el financiamiento de su capitalización, mientras que las economías menos desarrolladas si son dependientes de la importación de capital, pero además su FBKF releja una traslado adecuado de la IED a la FBKF, (ver gráfica 14).

\section{Conclusiones}

El análisis y los resultados de este documento, permiten formular diversas conclusiones relativas al comportamiento de los flujos de IED en las principales economías asiáticas durante el periodo 2005-2015. Dentro de la dinámica de la IED a nivel mundial, el papel de Asía aún es secundario, sin embargo la región está inserta en una senda de crecimiento y desarrollo progresivos, en el periodo 2005-2015 Estados unidos recibió el $14.6 \%$ de la IED, seguido de china con el $7.4 \%$, el cuarto lugar lo tiene Hong-Kong con el 5.4\%, el séptimo corresponde a Singapur con un $3.1 \%$ e India con $2.1 \%$ alcanza el diecisieteavo lugar 17. Como porcentaje del PIB, la IED y la FBKF muestran tendencias positivas y crecientes, lo que dejar ver una incidencia positiva de las EIED sobre la FBKF en la región.

Respecto al efecto de la crisis financiera subprime iniciada a finales de 2007, sobre los flujos de IED en la región de estudio, el efecto fue mínimo y heterogéneo tanto en intensidad, como en la duración del mismo; en general la IED de Asia no enfrentó las secuelas de la crisis, y en casos como China, la inestabilidad económica de Estados Unidos, genera un mayor atractivo de IED ganada por su solides económica y financiera.

Asia es una región bastante dinámica en sentido económico, pero las condiciones económicas de los diferentes países es disímil, mientras China se posiciona como nuevo referente de poder económico a nivel mundial, Bangladesh, Camboya y Vietnam aún presentan serios rezagos económicos; sin embargo, la IED se ha convertido en un impulso del desarrollo y crecimientos económicos, los países emergentes y economías en desarrollo han tomado medidas de cambio encaminadas a favorecer la movilidad de la inversión extranjera, tanto directa como de cartera, impulsando así el intercambio comercial.

En las agendas de gobierno de los países asiáticos, se plantea como prioridad la instauración de políticas que incentiven la EIED de forma sostenida, pues se han convencido de que contar con mecanismos adecuados y facilitadores de la IED, son base del desarrollo tecnológico, de la evolución de las empresas, de la cualificación del capital humano, del desarrollo de los mercados interno y externo y de una mejora en la calidad de vida de la población. El desarrollo de la ciencia y la tecnología amerita atención especial, ya que gran parte de los logos de Asia derivan de los progresos tecnológicos aplicados a sus industrias.

Si bien el estudio de los determinantes de la IED no es un tema reciente, su vigencia y relevancia actual es innegable; si bien los elementos de influencia en los flujos de IED han evolucionado de acuerdo al contexto histórico, los principales son los siguientes: las estabilidad política y social, la estabilidad macroeconómica, la búsqueda de nuevos mercados, la necesidad de explotación de recursos naturales, las características de la mano de obra (cualificación, costo, especialización, etc.), el desarrollo científico y tecnológico, la búsqueda de mayores tasas de ganancia, las características legales e institucionales del país receptor, las condiciones geográficas y el desarrollo de infraestructura.

\section{Referencias}

[1] UNCTAD. Informe sobre las inversiones en el mundo 2017, la inversión y la economía digital. Publicación de las Naciones Unidas, 2017; UNCTAD/WIR/2017, Recuperado de: http://unctad.org/es/Publications Library/wir2017_overview_es.pdf.

[2] Hymer, S. H. The international operations of national firms: a study of direct investment. Tesis Doctoral; Instituto Tecnológico de Massachusetts, Cambridge, Massachusetts; 1958.

[3] Vernon, R. (1966). International Investment an International Trade in the Product Cycle, Quarterly Journal of Economics, 1966; 80: 190-207.

[4] Helpman, E. y Krugman, P. Market Structure and Foreign Trade. Cambridge, Massachusetts, Instituto Tecnológico de Massachusetts Press; 1985.

[5] Kojima, K. Direct Foreign Investment: A Japanese Model of Multinacional Business Operations. Crom Helm, Londres; 1976.

[6] Dunning, J. H. Trade, location of economic activity and the Multinacional Enterprise: a search for an eclectic approach. En Ohlin B., Hesselborn P., Wijkman P., (eds.), The international allocation of economic activity, Londres, Inglaterra, MacMillan; 1977.

[7] Dunning, J. H. (1994). Re-evaluating the benefits of foreign direct investment. Transnational Corporations; 1994, 3 (1).

[8] OZAWA, T. Foreign Direct Investment and Economic Development. Transnational Corporations; 1992, 1 (1), 27-54.

[9] Shöholm, F. Foreign Direct Investments in Southeast Asia, IFN Working Paper 987, Research Institute of Industrial Economics Estocolmo, Suecia; 2013, Recuperado de: http://www.ifn.se/wfiles/wp/wp987.pdf. 
[10] BBVA. Las fuentes de crecimiento económico en Asia. Capital y Crecimiento Cuadernos de Fundación BBVA; 2010, no. 8. Recuperado de: https://w3.grupobbva.com /TLFU/dat/08_CyC_2010_web.pdf.

[11] Cortiñas, P. A. Las inversiones extranjeras directas en los países del sudeste asiático: los casos de Vietnam y Camboya. Universidad Pontificia Comillas, Madrid; 2015, Recuperado de:https://repositorio.comillas.edu /xmlui/handle/11 531/3774.

[12] Deorukhkar, S. y García H. A. Inversión extranjera directa de India: ¿de insignificante a relevante?, Artículo de prensa, Economía Exterior, BBVA Research; 2015, Recuperado el 19 de marzo de 2018 en: https://www.bbvaresearch.com/publi caciones/inversionextranjeradirecta-de-india-de-insignificante-a-relevante/.

[13] Correa L. G. y González G. J. (2006). La inversión extranjera directa: China como competidor y socio estratégico. Nueva sociedad; 2006, 203. 